\title{
PRESENÇA AFRICANA E ARRANJOS MATRIMONIAIS ENTRE OS ESCRAVOS EM CAMPOS DOS GOITACAZES (1790-1831)
}

African presence and marriage among the slaves at Campos dos Goitacazes (1790-1831)

Márcio de Sousa Soares*

\begin{abstract}
RESUMO
O artigo examina o impacto do tráfico atlântico sobre a população escrava nos Campos dos Goitacazes no auge da agroexportação do açúcar na capitania/província do Rio de Janeiro. Tem por objetivo analisar como a acentuada presença de africanos afetava os arranjos matrimoniais entre os escravos.
\end{abstract}

Palavras-chave: escravidão; africanos; casamento.

\begin{abstract}
In this article, is examined the impact of the transatlantic slave trade on the slave population of Campos dos Goitacazes during the sugar boom of the captaincy (later the province) of Rio de Janeiro. I study the effect the huge proportion of Africans in local slave population had on the marriage alliances established inside the slave group.
\end{abstract}

Key-words: slavery; Africans; marriage.

\section{A demografia da escravidão}

Foi no bojo do fortalecimento do circuito atlântico que ligava Angola ao Rio de Janeiro no comércio de almas - graças à abertura do

* Professor Adjunto do Curso de História da Universidade Federal Fluminense (Polo Universitário de Campos dos Goytacazes) e Pesquisador do CNPq 
porto de Luanda aos comerciantes estabelecidos no Brasil após 1715 - que se processaram a montagem e a expansão das atividades açucareiras nos Campos dos Goitacazes, a partir da segunda metade do século XVIII.

Enxameados por uma infinidade de lavradores dedicados ao cultivo da cana-de-açúcar e por centenas de pequenos e médios engenhos, os Campos dos Goitacazes se consolidaram como a principal área agroexportadora da capitania. Essa posição de destaque assumida por Campos no cenário da atividade açucareira pode ser percebida tanto pelo crescimento vertiginoso da quantidade de engenhos edificados na região quanto pelo volume de açúcar branco exportado via cidade do Rio de Janeiro e pela presença maciça de escravos ${ }^{1}$. É, portanto, à luz dessa vigorosa expansão das atividades açucareiras que devemos compreender a dinâmica do quadro demográfico apresentado pelos Campos dos Goitacazes no período analisado.
QUADRO I - ESTIMATIVAS DA PROPORÇÃO DE ESCRAVOS EM CAMPOS DOS GOITACAZES (1790-1836)

\begin{tabular}{c|c|c|c}
\hline Anos & Livres & Escravos & \% de Escravos \\
\hline 1799 & 14.447 & 19.058 & 56,9 \\
\hline 1816 & 14.560 & 17.357 & 54,3 \\
\hline 1821 & 17.280 & 19.234 & 52,7 \\
\hline 1836 & 21.123 & 30.595 & 59,2 \\
\hline
\end{tabular}

FONTE: (1799) Arquivo Público de Campos (APC) - Coleção Alberto Lamego - 19-69 - rolo 3. Mapas relativos às vilas da Capitania da Paraíba do Sul; um trazendo os nomes das ruas e número de casas de São Salvador e São João da Barra no ano de 1799; outro, a população, fábricas e escravos das diferentes freguesias de São Salvador dos Campos dos Goitacazes no mesmo ano; (1816) SAINT-HILAIRE, Auguste de. Viagem pelo distrito dos diamantes e litoral do Brasil. Belo Horizonte: Itatiaia, 1974, p. 202; (1821) ANRJ - Códice 808, v.4 - Mapa da População da Província do Rio de Janeiro em 1821; (1836) Ata da Sessão da Câmara Municipal de Campos dos Goitacazes em 22 de janeiro de 1836 apud FEYDIT, Júlio. Subsídios para a história dos Campos dos Goytacazes. Rio de Janeiro: Esquilo, 1979, p. 275.

Em face da expressividade das cifras apresentadas no Quadro I, estamos diante de um universo rural inelutavelmente modelado pela escra-

1 Sobre o aumento progressivo da quantidade de engenhos, cf. DONALD Jr., Cleveland. Slavery and Abolition in Campos, Brazil, 1830-1888. PhD. Thesis, Cornell University, 1973, p. 21-22; LARA, Sílvia H. Campos da violência: escravos e senhores na capitania do Rio de Janeiro, 1750-1808. Rio de Janeiro: Paz e Terra, 1988, p. 130-132 e FARIA, Sheila de Castro. A colonia em movimento: fortuna e família no cotidiano colonial. Rio de Janeiro: Nova Fronteira, 1998, p. 242. Sobre as exportações de açúcar, cf. ARRUDA, José Jobson de. O Brasil no comércio colonial. São Paulo: Ática, 1980, p. 351-361. 
vidão. A combinação perversa entre o desequilíbrio numérico entre homens e mulheres, os níveis avassaladores de mortalidade infantil e a baixa expectativa de vida impediam o crescimento natural da população cativa. Consequentemente, a manutenção e, sobretudo, a ampliação das escravarias eram solucionadas pelo comércio negreiro. Nesse sentido, tanto a expressividade percentual quanto o crescimento absoluto da população escrava em Campos sugerem uma forte incursão dos senhores locais no mercado de almas.

A expansão das atividades açucareiras em Campos incrementou uma demanda cada vez maior por braços, o que fez com que, nas três primeiras décadas do século XIX, os produtores ali estabelecidos se transformassem nos maiores compradores de africanos vendidos na Capitania/ Província do Rio de Janeiro: adquiriram nada menos do que 48,3\% de um total de 58.989 cativos $^{2}$.

No que diz respeito às procedências dessa enorme onda de cativos que inundou os Campos dos Goitacazes, os inventários post-mortem e os registros de batismo demonstraram - como era de se esperar - que a esmagadora maioria vinha da África Central Atlântica (Quadro II). Levando-se em conta as flutuações do tráfico de escravos desembarcados no porto do Rio de Janeiro, é possível perceber uma ligeira queda do percentual de cativos oriundos da África Central Atlântica, entre 1826-1831, provocada pelo aumento da presença dos pretos de nação moçambique entre os escravos africanos ${ }^{3}$. Todavia, é necessário frisar que, nesse período, os avaliadores dos espólios passaram a diferenciar os escravos estrangeiros dos nascidos no Brasil, quando o faziam, apenas com a fórmula "de nação".

Por outro lado, a análise dos registros de batismo revela que, nas três primeiras décadas do século XIX, os cativos recém-chegados identificados pelos padres como angolas constituíam $91,7 \%$ dos adultos com sacramento ministrado em São Salvador. Logo, os registros paroquiais não deixam a menor dúvida: a maior parte dos africanos, cuja origem não foi especificada nos inventários, era composta pelos pretos de nação angola.

2 Cf. FRAGOSO, João Luís Ribeiro; FERREIRA, Roberto Guedes. Tráfico interno de escravos e relações comerciais no Centro-Sul, séculos XVIII e XIX. Brasília. IPEA/ LIPHIS, 2001. CD-ROM.

3 De acordo com Florentino e Góes, em virtude das oscilações do volume de cativos aportados, o intervalo entre 1790-1808 pode ser considerado como um período de estabilidade dos desembarques; 1809-1825 como fase de expansão e, por fim, 1826-1831 marcado por uma sensível crise da oferta de africanos. Cf. FLORENTINO, Manolo; GÓES, José Roberto. A paz das senzalas: famílias escravas e tráfico atlântico, Rio de Janeiro, c. 1790-c. 1850. Rio de Janeiro: Civilização Brasileira, 1997, p. 47-49. 
QUADRO II - DISTRIBUIÇÃO DOS AFRICANOS INVENTARIADOS E BATIZADOS EM CAMPOS, POR ÁREAS DE PROCEDÊNCIA (1790-1831)

\begin{tabular}{|c|c|c|c|c|}
\hline \multicolumn{5}{|c|}{ Africanos inventariados } \\
\hline \multirow[b]{2}{*}{ Intervalo } & \multicolumn{3}{|c|}{ \% Macrorregião } & \multirow{2}{*}{$\begin{array}{l}\text { Total (números } \\
\text { absolutos) }\end{array}$} \\
\hline & \begin{tabular}{|c} 
África Central- \\
-Atlântica
\end{tabular} & África Ocidental & África Oriental & \\
\hline $1790-1808$ & 94 & 5 & 1 & 1.496 \\
\hline $1809-1825$ & 97 & 2 & 1 & 904 \\
\hline $1826-1831$ & 90 & 4 & 6 & 519 \\
\hline \multicolumn{5}{|c|}{ Africanos batizados na freguesia de São Salvador } \\
\hline \multirow[b]{2}{*}{ Intervalo } & & \% Macrorregião & & \multirow[b]{2}{*}{$\begin{array}{l}\text { Total (números } \\
\text { absolutos) }\end{array}$} \\
\hline & $\begin{array}{c}\text { África Central- } \\
\text {-Atlântica }\end{array}$ & África Ocidental & África Oriental & \\
\hline $1800-1831$ & 97,8 & 1,2 & 1 & 4.461 \\
\hline
\end{tabular}

FONTE: APC - Inventários post-mortem e ACMC - Batizados de escravos - Livros n. 7 ao 11.

Por se tratar de cativos procedentes da África, a esmagadora maioria dos 7.038 escravos adultos batizados em São Salvador entre março de 1800 e dezembro de 1831 era do sexo masculino, respondendo por $69,7 \%$ do total. Esse expressivo percentual observado em Campos certamente resultava da combinação entre uma oferta já em si bastante desequilibrada e a preferência dos senhores estabelecidos nas áreas agroexportadoras por braços masculinos.

O exame detalhado das escravarias arroladas nos inventários post-mortem permite traçar o perfil apresentado pela população escrava local. Para efeito de análise, foram consideradas crianças os escravos que possuíam no máximo 13 anos; adultos, os que se encontravam entre 14 e 49 anos e, por fim, os velhos com idade igual ou superior a 50 anos $^{4}$.

O desequilíbrio etário provocado pela presença maciça de adultos permeou todos os períodos demarcados, cuja proporção nunca foi inferior aos $60,0 \%$ (Quadro III). Tornava-se, por via de regra, sempre mais elevado nos extremos, ou seja, nas escravarias de pequeno e grande porte. A pre-

4 Utilizo as idades limites conforme os critérios adotados por Stuart Schwartz e Sheila de Castro Faria. Cf. SCHWARTZ, Stuart. Segredos internos: engenhos e escravos na sociedade colonial (15501835). São Paulo: Cia das Letras, 1988, p. 286 e FARIA, Sheila de Castro. A colonia em movimento..., p. 297. 
sença de dois ou três cativos de origem africana nas escravarias de menor porte era suficiente para projetar o percentual de adultos a níveis bastante elevados. Já no caso das grandes unidades produtivas, voltadas para a agroexportação, a elevada proporção de adultos estava diretamente vinculada à carência sempre e cada vez maior de braços para manutenção e/ou ampliação de suas atividades. Adicionem-se, além disso, os níveis avassaladores de mortalidade infantil e a baixa expectativa de vida - em grande parte fruto da rudeza das condições de trabalho - que agravavam ainda mais aquele desequilíbrio provocado pelo tráfico atlântico.

QUADRO III - FAIXA ETÁRIA DOS ESCRAVOS (1790-1831)

\begin{tabular}{c|c|c|c|c|c|c}
\hline \multirow{2}{*}{ Período } & \multicolumn{2}{|c|}{ Crianças } & \multicolumn{2}{c|}{ Adultos } & \multicolumn{2}{c}{ Velhos } \\
\cline { 2 - 7 } & $\#$ & $\%$ & $\#$ & $\%$ & $\#$ & $\%$ \\
\hline $1790-1808$ & 581 & 22,1 & 1.705 & 64,8 & 347 & 13,2 \\
\hline $1809-1825$ & 368 & 19,2 & 1.116 & 60,8 & 383 & 20,0 \\
\hline $1826-1831$ & 314 & 19,6 & 1.014 & 63,3 & 275 & 17.2 \\
\hline
\end{tabular}

FONTE: APC - Inventários post-mortem.

Os chamados escravos velhos responderam, no máximo, pela proporção de $20,0 \%$. Visto que, assim como as crianças, poucos deles eram traficados, sua discreta participação no conjunto das escravarias se deve, sobretudo, àqueles cativos que, além de conseguirem sobreviver aos rigores da travessia do Atlântico, ultrapassavam a fronteira dos 49 anos de idade não obstante a dureza de viver as agruras do cativeiro.

A forma como a presença maciça de escravos de origem africana determinava o desequilíbrio etário da população escrava pode ser dimensionada no próximo quadro. Não obstante a antiguidade da ocupação da região - e a quantidade expressiva de crioulos nas grandes unidades produtivas -, a escravidão em Campos no boom da atividade açucareira foi predominantemente adulta, masculina e africana. Fossem pequenas, médias ou grandes, todas as faixas de tamanho de escravarias sempre se mostraram, entre adultos e velhos, enormemente africanizadas. $\mathrm{O}$ ritmo acelerado de expansão da produção açucareira exigia sempre, e cada vez, mais braços de africanos adultos. 
QUADRO IV - FAIXA ETÁRIA E PROCEDÊNCIA DOS ESCRAVOS (1790-1831)

\begin{tabular}{c|c|c|c|c|c|c|c|c|c}
\hline \multirow{2}{*}{ Período } & \multicolumn{3}{|c|}{ Crianças } & \multicolumn{3}{c|}{ Adultos } & \multicolumn{3}{c}{ Velhos } \\
\cline { 2 - 11 } & AF & BR & \%AF & AF & BR & \%AF & AF & BR & \%AF \\
\hline $1790-1808$ & 28 & 553 & 4,8 & 1.142 & 465 & 71,1 & 248 & 65 & 79,2 \\
\hline $1809-1825$ & 7 & 359 & 1,9 & 615 & 398 & 60,7 & 249 & 36 & 87,3 \\
\hline $1826-1831$ & 21 & 286 & 6,8 & 489 & 356 & 57,9 & 148 & 66 & 69,1 \\
\hline
\end{tabular}

FONTE: APC - Inventários post-mortem.

A íntima relação entre o acesso ao tráfico atlântico de escravos e a agroexportação determinou as expressivas proporções de africanos nas escravarias locais em todos os períodos estudados, mesmo entre aqueles pequenos produtores voltados para o cultivo de alimentos que, sempre que podiam e julgavam conveniente adquirir um cativo, decerto se beneficiavam daquela enxurrada de negros que passou a inundar a região anualmente.

Se, pelas cifras apresentadas no Quadro IV, o percentual de africanos entre a população adulta contraditoriamente decresce nos períodos de expansão e crise da oferta, isso não deve ser atribuído tão somente ao relativo crescimento do contingente de crioulos, mas também a uma maior frouxidão no rigor dos avaliadores na descrição dos escravos inventariados ${ }^{5}$. Contudo, os registros de batismo não deixam nenhuma margem de dúvida: a maioria esmagadora daqueles escravos vinha de Angola. Dito de outra forma, se as proporções de centro-africanos entre os adultos já se mostravam significativamente elevadas até 1825 , certamente que, ao contrário do que os inventários dão a conhecer, elas aumentaram ainda mais a partir daquele ano. Enquanto a proporção de pretos de nação era extremamente alta naquele segmento da população escrava com mais de 50 anos, o inverso acontecia com as crianças pelas razões sobejamente conhecidas.

Tudo leva a crer que a elevada concentração de escravos de uma "mesma" nação - que tanto inquietava governantes locais, autoridades metropolitanas e viajantes estrangeiros - não se converteu em objeto de

5 De 1790 até 1808 , os escravos inventariados sem origem identificada não ultrapassaram a casa dos $10 \%$ do total. Entre 1809 e 1825 havia duas crianças, 153 adultos e 98 velhos sem identificação de procedência. Por fim, entre 1826 e 1831, contaram-se sete crianças, 169 adultos e 61 velhos com origem ignorada. É bastante provável que a maior parte desses adultos e velhos fosse composta por africanos. 
maiores preocupações dos senhores estabelecidos em Campos $^{6}$. Haja vista a presença esmagadora dos pretos de nação angola entre os escravos da região, é provável que os senhores locais tenham se valido das rivalidades e disputas entre crioulos e africanos, o que certamente não exclui a possibilidade da existência de dissensões étnicas ocultadas pelo rótulo senhorial "nação angola" entre os cativos de origem africana. De todo modo, a questão do investimento senhorial na diversidade étnica das escravarias sugerida por governantes e observadores estrangeiros merece maiores investigações, até mesmo porque, dependendo da época ou lugar, a realização de eventuais projetos senhoriais dessa natureza esbarrava nos limites impostos pelo tráfico atlântico.

A presença maciça de africanos entre os escravos adultos e velhos era responsável pelo sensível desequilíbrio entre os sexos nas referidas faixas de idade. Como a historiografia tem demonstrado, os efeitos mais perversos deste aspecto estrutural da população cativa eram a dificuldade para muitos homens adultos encontrarem parceiras e as taxas negativas de crescimento natural das escravarias?

Se durante a fase de estabilidade dos desembarques de africanos no porto do Rio de Janeiro o desequilíbrio entre homens e mulheres (adultos e velhos) já era alto, foi durante a fase de expansão do tráfico, com era de se esperar, que se verificaram as proporções masculinas mais elevadas, sobretudo entre aqueles cativos adultos que viviam nas médias e grandes unidades produtivas.

QUADRO V - SEXO E FAIXA ETÁRIA DOS ESCRAVOS (1790-1831)

\begin{tabular}{l|l|l|l|l|l|l|l|l|l}
\hline \multirow{2}{*}{ Período } & \multicolumn{4}{|l|}{ Crianças } & \multicolumn{4}{|l|}{ Adultos } & \multicolumn{3}{l}{ Velhos } \\
\cline { 2 - 10 } & $\mathrm{H}$ & $\mathrm{M}$ & $\% \mathrm{H}$ & $\mathrm{H}$ & $\mathrm{M}$ & $\% \mathrm{H}$ & $\mathrm{H}$ & $\mathrm{M}$ & $\% \mathrm{H}$ \\
\hline $1790-1808$ & 271 & 309 & 46,7 & 1.100 & 605 & 64,5 & 251 & 96 & 72,3 \\
\hline $1809-1825$ & 183 & 185 & 49,6 & 779 & 387 & 66,8 & 268 & 115 & 70,0 \\
\hline $1826-1831$ & 156 & 157 & 49,8 & 623 & 391 & 61,4 & 179 & 96 & 65,1 \\
\hline
\end{tabular}

FONTE: APC - Inventários post-mortem.

6 Sobre a aposta de várias autoridades na dissensão étnica para o governo dos escravos cf. LARA, Sílvia H. Fragmentos setecentistas: escravidão, cultura e poder na América portuguesa. São Paulo: Cia das Letras, 2007, p. 158-163.

7 Cf., entre outros, SCHWARTZ, Stuart. Segredos internos..., p. 286 et passim e FLORENTINO, Manolo; GÓES, José Roberto. A paz das senzalas..., p. 148-150. 
O desequilíbrio entre homens e mulheres mostra-se mais profundo quando se observam, em conjunto, as procedências e as faixas etárias. A tendência apontada pelos inventários indica que essa desproporção era bem menor entre os escravos nascidos no Brasil, muito embora também entre eles a proporção de homens adultos fosse ligeiramente superior à de mulheres na mesma faixa etária ${ }^{8}$. Mas era entre os africanos que essa desproporção atingia níveis avassaladores.

QUADRO VI - SEXO, NATURALIDADE E FAIXA ETÁRIA DOS ESCRAVOS (1790-1831)

\begin{tabular}{|c|c|c|c|c|c|c|c|c|}
\hline \multirow{3}{*}{ Faixa Etária } & \multicolumn{8}{|c|}{$1790-1808$} \\
\hline & \multicolumn{4}{|c|}{ AFRICANOS } & \multicolumn{4}{|c|}{ NASCIDOS NO BRASIL } \\
\hline & $\overline{\mathrm{H}}$ & $\bar{M}$ & Total & $\% \mathrm{H}$ & $\overline{\mathrm{H}}$ & $\bar{M}$ & Total & $\% \mathrm{H}$ \\
\hline Crianças & 18 & 10 & 28 & 64,3 & 253 & 299 & 552 & 45,8 \\
\hline Adultos & 788 & 354 & 1.142 & 69,0 & 256 & 209 & 465 & 55,0 \\
\hline Velhos & 196 & 52 & 248 & 79,0 & 38 & 28 & 66 & 57,5 \\
\hline \multirow{3}{*}{ Faixa Etária } & \multicolumn{8}{|c|}{$1809-1825$} \\
\hline & \multicolumn{4}{|c|}{ AFRICANOS } & \multicolumn{4}{|c|}{ NASCIDOS NO BRASIL } \\
\hline & $\mathrm{H}$ & M & Total & $\% \mathrm{H}$ & $\overline{\mathrm{H}}$ & $\overline{\mathrm{M}}$ & Total & $\% \mathrm{H}$ \\
\hline Crianças & 6 & 1 & 7 & 85,7 & 175 & 184 & 359 & 48,7 \\
\hline Adultos & 471 & 144 & 615 & 76,6 & 216 & 182 & 398 & 54,3 \\
\hline Velhos & 188 & 61 & 249 & 75,5 & 24 & 12 & 36 & 66,7 \\
\hline \multirow{3}{*}{ Faixa Etária } & \multicolumn{8}{|c|}{$1826-1831$} \\
\hline & \multicolumn{4}{|c|}{ AFRICANOS } & \multicolumn{4}{|c|}{ NASCIDOS NO BRASIL } \\
\hline & $\mathrm{H}$ & $\mathrm{M}$ & Total & $\% \mathrm{H}$ & $\overline{\mathrm{H}}$ & $\mathrm{M}$ & Total & $\% \mathrm{H}$ \\
\hline Crianças & 11 & 10 & 21 & 52,4 & 141 & 144 & 285 & 49,5 \\
\hline Adultos & 349 & 140 & 489 & 71,4 & 169 & 187 & 356 & 47,5 \\
\hline Velhos & 112 & 36 & 148 & 75,7 & 37 & 29 & 66 & 56,0 \\
\hline
\end{tabular}

FONTE: APC - Inventários post-mortem.

8 Na amostragem relativa ao período situado entre 1826 e 1831, entre os escravos adultos a proporção de homens nascidos no Brasil era inferior à de mulheres, o que deriva do fato de a escravaria do capitão Paulo Francisco da Costa Viana contar com 359 escravos nascidos no Brasil, 180 africanos e 126 de procedência ignorada. Ainda que supuséssemos que todos os escravos de origem desconhecida fossem africanos, o número de escravos nascidos no Brasil seria ligeiramente superior. 
Essa estrutura mostrava-se ainda mais adversa aos nascidos na África quando se observa a razão de masculinidade nesse segmento da população cativa. Note-se que os inventários sugerem que, entre os escravos nascidos no Brasil, o desequilíbrio entre os sexos era sempre muito menor com relação aos africanos, chegando a ponto de haver mais mulheres do que homens nas pequenas escravarias. Em contrapartida, a situação não só era extremamente desfavorável aos africanos como se agravou bastante ao longo do tempo, na medida em que cada vez mais os senhores recorriam ao tráfico atlântico para a montagem de seus empreendimentos e/ou reposição da mão de obra.

QUADRO VII - RAZÃO DE MASCULINIDADE ENTRE ESCRAVOS ADULTOS (17901831)

\begin{tabular}{c|c|c}
\hline Período & AFRICANOS & NASCIDOS NO BRASIL \\
\hline $1790-1808$ & 222 & 122 \\
\hline $1809-1825$ & 327 & 118 \\
\hline $1826-1831$ & 249 & 90 \\
\hline
\end{tabular}

FONTE: APC - Inventários post-mortem.

Adulta, africana e masculina eram as características que determinaram o ethos do perfil demográfico da população escrava nas áreas agroexportadoras e, como tal, Campos não fugiu a essa regra.

\section{Os arranjos matrimoniais}

Os estudos sobre a família escrava no Brasil têm ressaltado as vantagens do parentesco para os cativos, assim como os enormes obstáculos que os mesmos tinham que enfrentar para a constituição de laços conjugais?. No terreno das dificuldades, sublinham-se não só o acentuado desequilíbrio estrutural entre os sexos em relação aos africanos, como também a visível

9 Para uma síntese da produção historiográfica sobre as dificuldades e vantagens do casamento entre escravos, cf. GUEDES, Roberto. Egressos do cativeiro: trabalho, família, aliança e mobilidade social. Rio de Janeiro: Mauad, 2008, p. 145-170. 
interferência senhorial que restringia as uniões sacramentadas ao âmbito interno de cada escravaria. Dos 2.946 casamentos de escravos celebrados entre 1800 e 1831, em que há informação sobre quem eram os senhores, nada menos do que 2.912 pertenciam ao mesmo dono $(98,8 \%)$, enquanto apenas 34 referiam-se a escravos de senhores diferentes $(1,2 \%)^{10}$. A Igreja desaprovava expressamente a separação de casais, uma vez que o título 71 do Livro I das Constituições Primeiras do Arcebispado da Bahia rezava o seguinte:

Conforme o direito divino e humano os escravos e escravas podem casar com outras pessoas cativas ou livres e seus senhores não podem impedir o matrimônio nem o uso dele em tempo e lugar conveniente, nem por esse respeito os pode tratar pior, nem vender para onde o outro por ser cativo ou ter outro justo impedimento o não possam seguir e fazendo o contrário pecam mortalmente $[\ldots]$.

Por se tratar de uma relação pessoal de dominação, os senhores faziam de tudo para afastar ao máximo qualquer possibilidade de qualquer intervenção externa no governo dos escravos. Não é difícil imaginar os possíveis transtornos derivados da mobilidade espacial ou de transações de compra e venda de escravos casados pertencentes a donos diferentes.

Não menos difíceis eram os enlaces envolvendo escravos e libertos.

Aos vinte e sete dias do mês de novembro do ano de nascimento de Nosso Senhor Jesus Cristo de mil e oitocentos e dezoito, o escravo João, preto de nação ganguela, recebeu carta de alforria de Vicente Ferreira Gomes pelo valor de $40 \$ 000$ réis. Dois anos depois, agora identificado como João Angola, acertou casamento com Florência, preta de nação angola, escrava de Francisco Mendes ${ }^{11}$.

Não se tratava de uma situação comum, pois, em geral, os arranjos matrimoniais eram alinhavados entre "gente da mesma igualha", quer pela condição jurídica, quer pela extração social dos nubentes. Tanto era assim

10 Esses percentuais são extremamente semelhantes aos verificados na segunda metade do século XVIII. Cf. FARIA, Sheila de Castro. A colônia em movimento..., p. 314 e 316.

11 Arquivo da Cúria Metropolitana de Campos (ACMC) - Processo de Banhos de Casamento de João preto liberto e Florência preta cativa, 1820. 
que, entre janeiro se 1800 e dezembro de 1831, foram celebrados 2.998 casamentos entre escravos na freguesia de São Salvador, ao passo que somente 74 escravos se casaram com mulheres forras ou livres e apenas 45 escravas se casaram com forros ou livres. Ou seja, ao todo, as uniões mistas representavam apenas $4,0 \%$ dos casamentos de escravos ${ }^{12}$. Para o cônjuge livre, a união com um escravo representava um rebaixamento social, uma vez que para os homens forros, por exemplo, o matrimônio com uma escrava comprometia a existência ou a condição jurídica da prole. Não por acaso, ao rastrear a presença de alguns desses casais nos registros paroquiais não localizei registros de batismo, pois muito provavelmente não tiveram filhos, como foi o caso de João e Florência ${ }^{13}$.

Como o casamento pressupunha a coabitação, para ser sacramentado pelas bênçãos da Igreja o enlace matrimonial entre João e Florência teve que contar com o expresso consentimento e licença do senhor dela. Além disso, do preto João foi exigido pela Igreja que assinasse um termo de seguimento à escravidão, pelo qual "se obrigava a seguir a escravidão de sua futura consorte Florência escrava para qualquer parte que seus senhores a mandassem"14. Uma vez habilitados, uniram-se sob as bênçãos da Igreja em dezoito de novembro de 1820.

Como se vê, os africanos adultos enfrentavam enormes dificuldades para encontrar parceiras disponíveis ao casamento sacramentado pela Igreja e até mesmo para as uniões consensuais estáveis com escravas de outros senhores. Há diversos processos-crime para a região sobre agressões e assassinatos de escravos que se arriscaram a ultrapassar os limites das

12 ACMC - Casamentos de Escravos - Livros n. 2 ao n. 4 e Casamentos de Livres - Livros n. 4 e n. 5 . Sobre a raridade de casamentos mistos entre forros e escravos, Cf. LIMA, Carlos Alberto Medeiros. Entre duas estratégias patriarcais: casamentos de libertos na cidade do Rio de Janeiro, 1803-1834. Cativeiro \& Liberdade. Rio de Janeiro, Ano II, n. 5, jan./jun. 1997, p. 45-63.

13 Em suas análises sobre os casamentos mistos, Cacilda Machado chama a atenção para o fato de que, em uma sociedade escravista, nem sempre a mobilidade social era retilínea na direção ascendente. Com efeito, a autora se deparou com situações nas quais homens forros ao se casarem com escravas conduziam seus filhos ao cativeiro. A observação de Machado é importante porque corrige a impressão de que a mobilidade social dos libertos era sempre para cima. Entretanto, pode-se acrescentar que a própria dinâmica das relações sociais e o horizonte da alforria se encarregavam de fazer com que semelhante rebaixamento social dos rebentos reduzidos à condição escrava não significasse necessariamente um destino irremediável. Cf. MACHADO, Cacilda. A trama das vontades: negros, pardos e brancos na construção da hierarquia social do Brasil escravista. Rio de Janeiro: Apicuri, 2008.

14 ACMC - Processo de Banhos de Casamento de João preto liberto e Florência preta cativa, 1820. 
fazendas e sítios alheios em busca de companhia feminina ${ }^{15}$. Todos eles revelam a existência de uma enorme competição e rivalidade entre os cativos por conta da escassez de mulheres. Em fevereiro de 1821, por exemplo, Claudiana, preta escrava de José Dias da Costa Lima, foi agredida no rosto por "Eleutério pardo que mora atrás do Rosário às Ave-Marias de ontem quatorze do corrente mês e ano no lugar do Porto chamado Carneiro nesta Vila [de São Salvador] com um porrete". Uma das testemunhas chamadas para depor jurou aos santos evangelhos que o motivo da porretada decorreu de o agressor "achá-la em matos com um preto"16.

Como qualquer casamento pressupõe sempre uma escolha, para além dos limites impostos pela demografia e pela vontade senhorial, deve-se também levar em conta as preferências dos escravos. Refiro-me, especificamente, à fortíssima tendência para a endogamia conforme as procedências. Do total de 1.741 casamentos registrados entre 1750 e 1799, não foram considerados os casos em que se ignora a procedência dos nubentes, o que significa dizer que o universo de análise abarca $81,5 \%$ das uniões. Com relação aos 2.949 matrimônios registrados entre 1800 e 1831, descontando-se os casos em que a procedência dos noivos é ignorada, chegou-se a um percentual de $80,8 \%$. Uma vez constatado que a maioria esmagadora dos escravos africanos em Campos era composta pelos pretos de nação angola, para efeito de análise dos casamentos agreguei todos eles sob a rubrica de "africanos", assim como os pardos, mulatos e cabras foram classificados como "crioulos".

Em todo o período estudado, a endogamia sempre apresentou índices bastante elevados, cujo patamar mínimo nunca foi inferior a 77,8\%, atingindo o percentual de $83,1 \%$ no período em que os senhores recorreram com maior intensidade ao tráfico atlântico ${ }^{17}$. Os inventários indicaram que, com exceção do intervalo compreendido entre 1826 e 1831, o número de africanas adultas superava a quantidade de escravas nascidas no Brasil, o

15 Cf. KJERFVE, Tânia Maria Gomes Nery. Família e escravidão no Brasil Colonial - Campos, século XVIII. Dissertação (Mestrado) - Universidade Federal Fluminense. p. 182-185. Niterói, 1995. Infelizmente, a autora não atentou para as naturalidades das vítimas nem dos agressores.

16 BNRJ - Seção Manuscritos - Devassa pelos ferimentos feitos em Claudiana, escrava de José Dias da Costa Lima, 1821 - II, 34, 22, 45B.

17 Sobre a endogamia por grupos de procedência em Campos no século XVIII, cf. KJERFVE, Tânia Maria Gomes Nery. Família e escravidão no Brasil Colonial..., p. 167. 


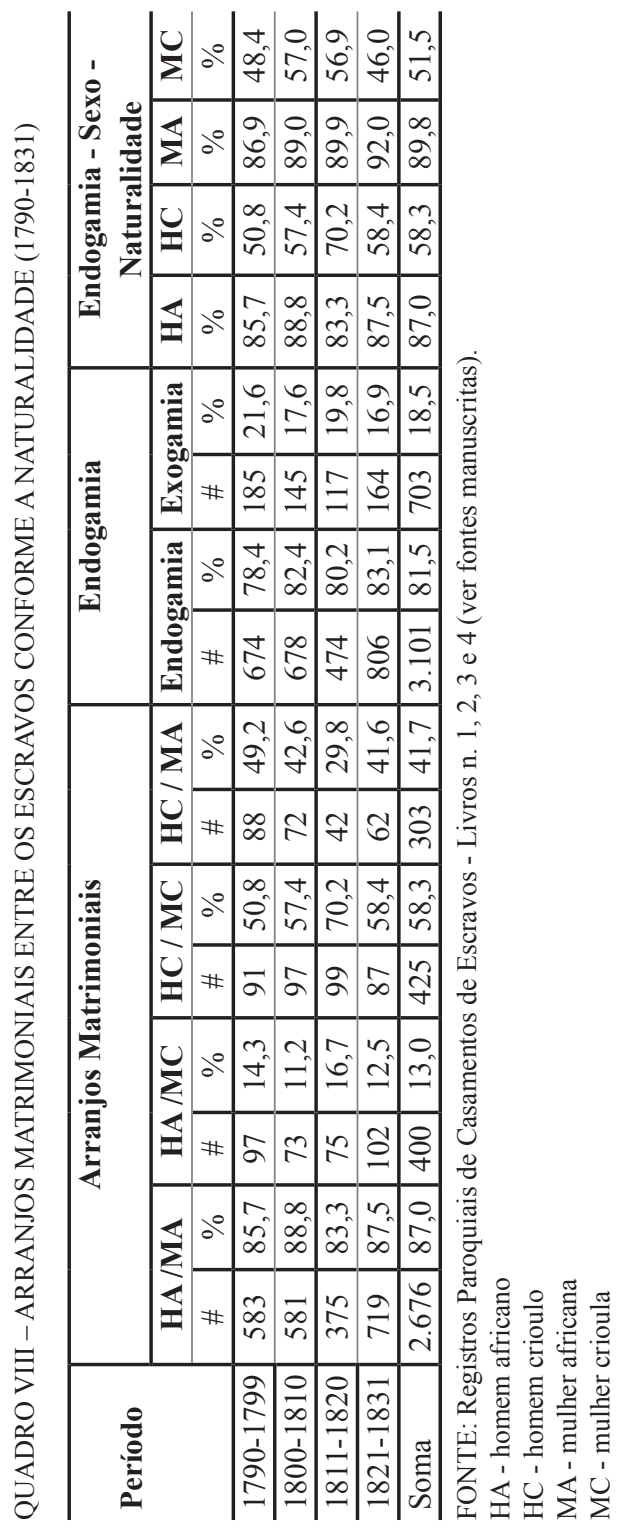


que certamente, e em larga medida, explica os elevadíssimos percentuais de endogamia entre os africanos e africanas. Contudo, o fenômeno não pode ser reduzido exclusivamente aos imperativos de ordem demográfica, uma vez que, no final da década de 1820, a quantidade de "crioulas" superava o número de africanas e, mesmo assim, a endogamia atingiu o patamar de $87,5 \%$ entre os homens africanos. Ou seja, havia espaço para a escolha, o que significa dizer que as preferências e restrições por parte dos escravos também tinham sua parcela de responsabilidade na produção da endogamia ${ }^{18}$.

Uma vez considerada a combinação entre a desproporção elevada entre africanos e africanas, as restrições senhoriais aos casamentos para além de seus domínios e as idiossincrasias dos escravos, conclui-se que o casamento era um recurso acessível a um número bastante limitado de homens africanos ${ }^{19}$. Tanto que, entre 1800 e 1831, foram registrados 4.902 batizados de escravos homens africanos na Matriz de São Salvador e apenas 1.953 se casaram na mesma igreja, o que equivale a 39,8\% daquele total. Mas, ao contrário do que possa parecer, trata-se de um percentual muito expressivo, pois, não obstante o desequilíbrio demográfico provocado pelo crescente fluxo de homens africanos, a proporção de escravos nascidos de legítimo matrimônio manteve-se num patamar bem alto. Contei 10.949 batismos de crianças escravas, ministrados entre 1799-1831, dos quais nada menos que $47 \%$ indicavam nascimentos legítimos.

No geral, os escravos nascidos no Brasil eram um pouco menos avessos à exogamia do que os africanos, embora a endogamia também fosse a regra entre eles. Todavia, nota-se uma sensível diferença de comportamento entre os sexos, considerando-se que, ao longo do tempo, assiste-se a uma tendência de queda da endogamia entre as "crioulas".

Ao que parece, em matéria de casamento, africanos e africanas nutriam um forte desprezo contra os escravos nascidos no Brasil, haja vista os enormes percentuais de endogamia entre eles. Embora a recíproca também fosse verdadeira, os "crioulos" tinham menos dificuldades para

18 Sobre a forte tendência para a endogamia entre os escravos em regiões e períodos distintos, cf. FLORENTINO, Manolo; GÓES, José Roberto. A paz das senzalas..., p. 147-152 e GUEDES, Roberto. Egressos do cativeiro..., p. 159-170.

19 Florentino e Góes ainda chamam a atenção para o fato de que os escravos mais velhos regravam o acesso às mulheres mais jovens em seu favor, limitando a margem de escolha dos escravos mais jovens, para os quais sobravam as mulheres mais velhas. Cf. FLORENTINO, Manolo; GÓES, José Roberto. A paz das senzalas..., p. 152-159. 
aparar suas arestas com os africanos. Observe-se que, entre os escravos nascidos no Brasil, o desequilíbrio entre homens e mulheres era bem menor - a ponto de, por vezes, a quantidade de mulheres superar o número de homens - e, mesmo assim, no geral, 41,7\% dos homens "crioulos" uniram-se às mulheres africanas. Possivelmente, esses escravos nascidos no Brasil viam-se obrigados a procurar seus consortes entre os de origem africana, por conta da combinação entre o limite do raio de escolha de um cônjuge estar circunscrito à escravaria a qual se pertencia e as interdições impostas pela Igreja ao casamento entre pessoas aparentadas até o quarto grau de consanguinidade ou vinculadas pelo compadrio ${ }^{20}$. Nesse terreno, os crioulos certamente encontravam maiores dificuldades do que os africanos para encontrar parceiros desimpedidos e, portanto, aptos ao casamento, embora alguns contraentes obtivessem da Igreja a dispensa dos impedimentos canônicos para se casar, sobretudo em decorrência da "cópula ilícita"21.

Com tudo e por tudo, diante de tamanhas dificuldades para a composição dos arranjos matrimoniais, o casamento tornou-se um dos fatores que promoviam a hierarquização entre os escravos. Se, como sublinhou Hebe Mattos, o matrimônio era um privilégio que aproximava os escravos mais antigos de uma experiência de liberdade que potencializava a obtenção de outros favores senhoriais - tais como uma roça ou a habitação numa senzala separada - então a família e o parentesco dela decorrente podem ser considerados esteios importantes para os escravos conseguirem transitar do cativeiro para a liberdade ${ }^{22}$.

Não creio, portanto, que as fortes afinidades linguísticas e cosmológicas que caracterizavam os povos centro-africanos tenham sido suficientes para cimentar uma identidade política entre os escravos, como

20 Os registros de batizados de escravos na freguesia de São Salvador, assentados entre 1753 e 1788 , revelam que $14,2 \%$ dos compadres eram escravos do mesmo dono, ao passo que na freguesia de São Gonçalo esse percentual era de 16,9\% entre 1770 e 1786. Cf. FARIA, Sheila de Castro. A colônia em movimento..., p. 321. Todavia, Ana Lugão Rios demonstrou, por meio do cruzamento de dados dos registros paroquiais com os inventários de grandes proprietários, que nessas unidades - nas quais a princípio eram maiores as chances dos escravos se casarem - o percentual de cativos aparentados espiritualmente era bem maior. Cf. RIOS, Ana Maria Lugão. Família e transição: famílias negras em Paraíba do Sul, 1872-1920. Dissertação (Mestrado) - Universidade Federal Fluminense. p. 55. Niterói, 1980.

21 Sobre as dispensas dos impedimentos matrimoniais franqueadas pela Igreja, cf. FARIA, Sheila de Castro. A colonia em movimento..., p. 58-61 e 312-314.

22 Cf. MATTOS, Hebe. Das cores do silêncio: os significados da liberdade no sudeste escravista - Brasil séc. XIX. Rio de Janeiro: Arquivo Nacional, 1995, p. 140-142 et passim. 
sugeriu Robert Slenes ${ }^{23}$. Se, por um lado, a imagem proposta por Manolo Florentino e José Roberto Góes da existência de um virtual "estado de guerra" entre os escravos me parece um tanto quanto exagerada, por outro, as divergências e a competição pelo acesso a recursos escassos - entre os quais o casamento - parecem ter, de fato, rendido uma eficiência política muito grande em favor dos senhores no que diz respeito à reprodução da ordem escravista $^{24}$. O que não significa dizer que não houvesse ganhos para os escravos. Ganhos diferenciados e muitas vezes precários, é verdade, mas decisivos para produzir um quantum mínimo de estabilidade social. Em matéria do governo dos escravos, é bastante provável que os senhores já soubessem que prudência e caldo de galinha não fazem mal a ninguém.

Recebido em 26/10/2009. Aprovado em 23/04/2010.

23 Cf. SLENES, Robert. A Árvore de Nsanda transplantada: cultos kongo de aflição e identidade escrava no sudeste brasileiro (século XIX). In: LIBBY, Douglas Cole; FURTADO, Júnia Ferreira. Trabalho livre, trabalho escravo: Brasil e Europa, séculos XVIII e XIX. São Paulo: Annablume, 2006, p. 273-314.

$24 \mathrm{O}$ assunto tornou-se objeto de acirrada polêmica entre os historiadores. Para um resumo das principais linhas de interpretação do assunto propostas por Robert Slenes, Hebe Mattos e Florentino e Góes, cf. FARIA, Sheila de Castro. Sinhás pretas, damas mercadoras: as pretas minas nas cidades do Rio de Janeiro e de São João del Rei (1700-1850). Tese (Concurso para Professor Titular em História do Brasil) - Universidade Federal Fluminense. p. 35-61. Niterói, 2004. 